\title{
ON THE MOULT IN THE STOAT, MUSTELA ERMINEA LINNAEUS, 1758, FROM THE NETHERLANDS
}

\author{
by
}

\author{
R. W. M. VAN SOEST \& P. J. H. VAN BREE \\ Zoological Museum, University of Amsterdam
}

\section{INTRODUCTION}

Little data can be found on the exact moult pattern of the Stoat, Mustela erminea Linnaeus, 1758. Most of the information concerning this process has been supplied by authors, who were able to keep Stoats in captivity for some time (Psenner, 1942; Rothschild, 1942; Schmidt, 1954; Herter, 1958; Rust, 1962). The results of these observations do not accord with one another, due, no doubt, to the artificial circumstances.

Those, who approached the problem by studying museum-material (Krumbiegel, 1935; Frechkop, 1954) were greatly limited in their conclusions by the shortage of pelts in the collections. Krumbiegel (loc. cit.) showed, that Stoats in the same period of the year in different localities are not necessarily in the same moulting stage, and furthermore that moulting starts at the protruding parts of the animal (margin of the ears, snout, feet and tail). Frechkop suggests from studies made of pelts of different Mustelidae, that in the moult pattern of the Stoat, one can observe a reversed replica of the striped skin pattern of related genera (e.g., Poecilogale, Ictonyx).

To check these assumptions is one of the purposes of our study. Other aspects of the moult of the Stoat, such as the starting and finishing date of both $\mathrm{Au}$ tumn and Spring moults, differences between males and females in this respect, and differences between Stoats of relatively colder parts of the Netherlands and relatively warmer parts, will also be dealt with in this paper.

\section{MATERIAL}

The material consisted of 300 pelts from the collections of the Zoological Museum (Zoölogisch Museum) in Amsterdam and the State Museum of Natural History (Rijksmuseum van Natuurlijke Historie) at Leiden. Of these, 146 were from animals captured at the dune region between Beverwijk and Bergen aan Zee (province of North-Holland) on the occasion of a joint research project on Mustela erminea with the Institute of Biological Field Research (ITBON) at Arnhem, during the years 1965, 1966 and 1967. This collection was the basis of the determination of the exact moult pattern, since the animals were collected in the same locality in all periods of the year.

The authors wish to express their gratitude towards Dr. A. M. Husson for enabling them to study the Mustela erminea collection of the State Museum of Natural History, towards Drs. W. J. Doude van Troostwijk and other staffmembers of the ITBON and towards the management of the Provinciaal Waterleidingbedrijf van Noord-Holland (P.W.N.) and the gamewardens of this company for their cooperation in this study.

\section{RESULTS}

1. Determination of the exact Moult pattern (figs. 1 and 2).

For the purpose of demonstrating the subsequent stages in the moulting of the Stoat, 44 animals were chosen and are arranged in fig. 1 (Autumn moult) and fig. 2 (Spring moult).

Autumn moult starts at the base of the tail, followed by fore- and hindlegs, shoulders and earmargins. After this, the whitening ascends from the sides, finally leaving only a thin dorsal line, a patch on the hind quarters and the head in the original brown colour. Of these, the dorsal line and the patch on the hind quarters disappear almost simultaneously, while the head (and some sparse dorsal hairs) stays brown. The whitening of the head ends at the eyes. The authors agree with Krumbiegel (1935), that even fully moulted animals in white wintercoat keep a very indefinite brown ring round the eyes (not illustrated in our figures).

Spring moult. One can easily observe, that Spring moult follows the same pattern as Autumn moult but in reverse order. 

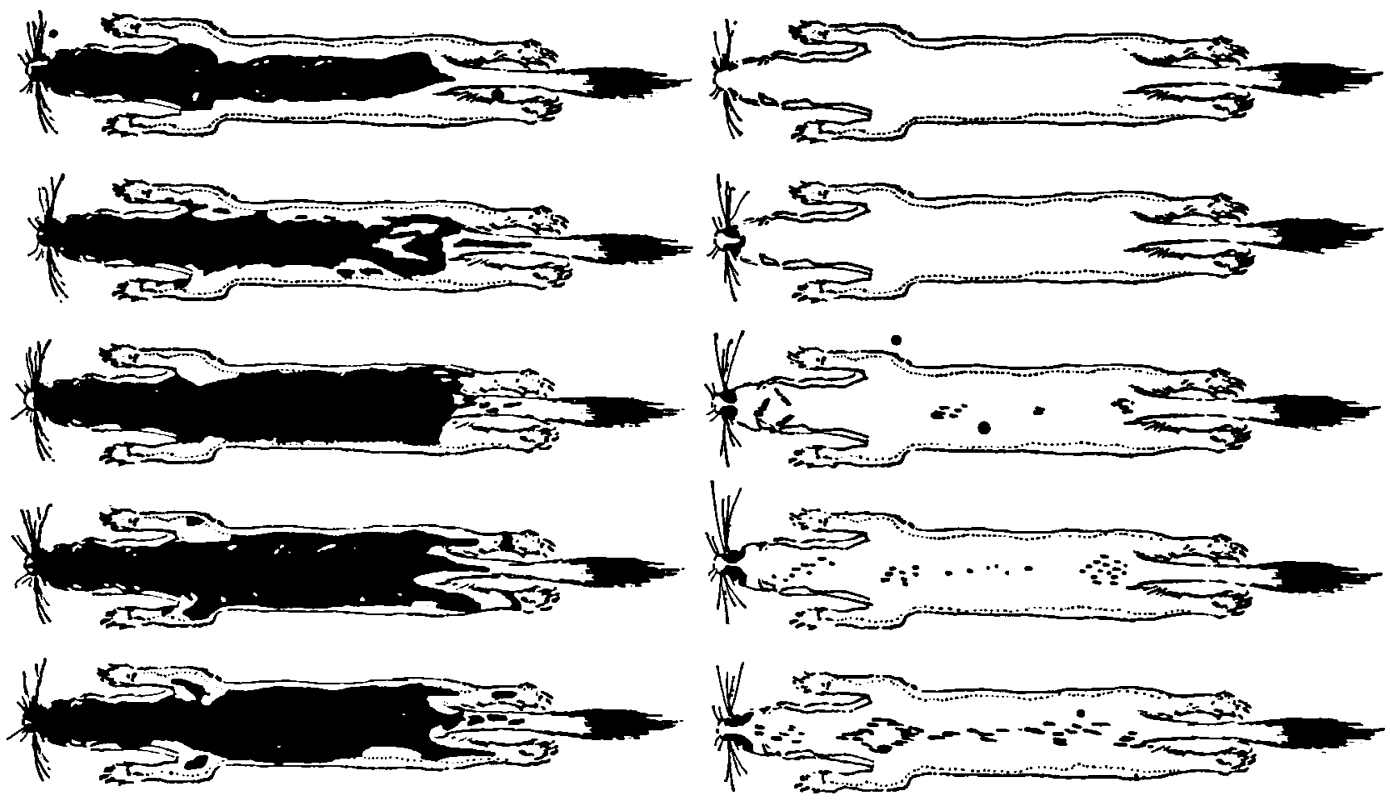

16

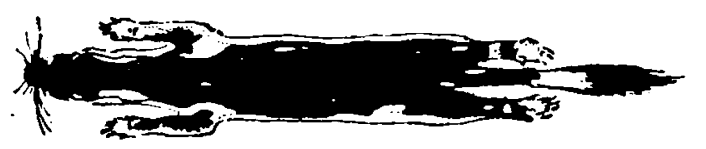

$\lim _{x \rightarrow 2}$

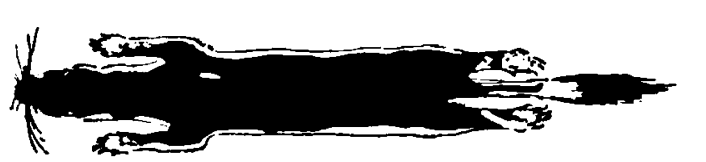

4
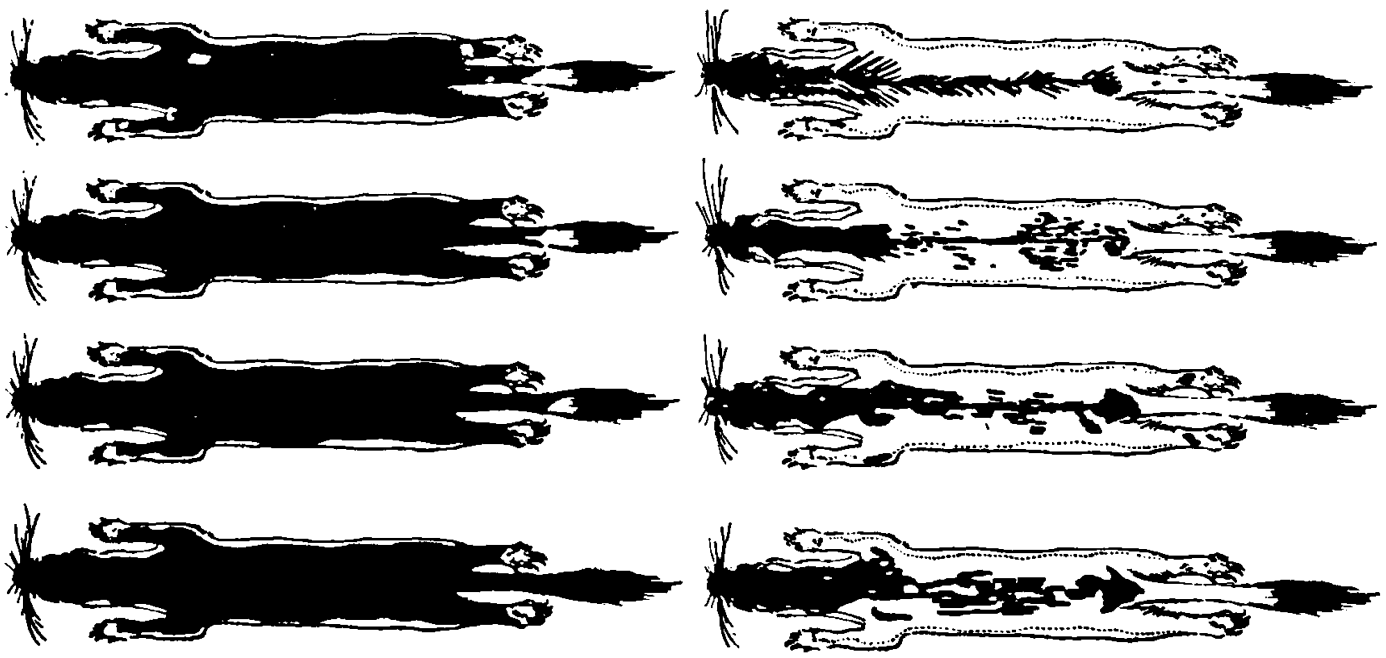


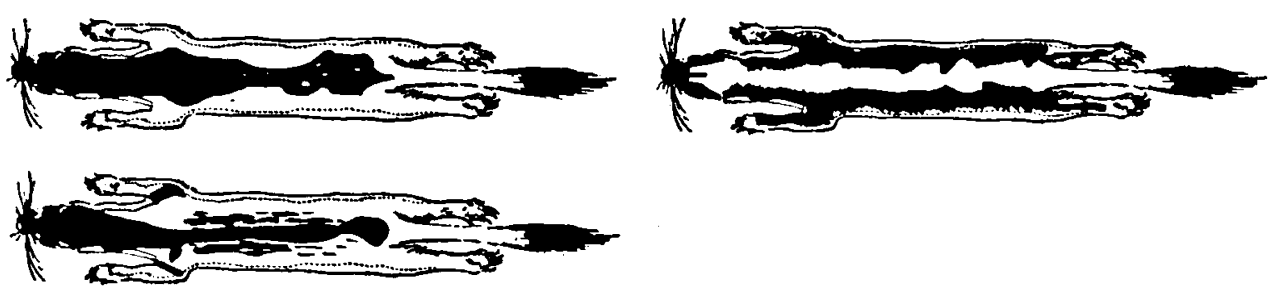

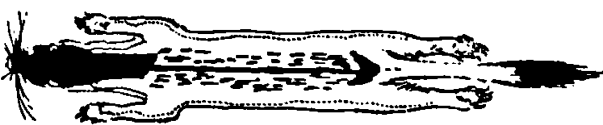
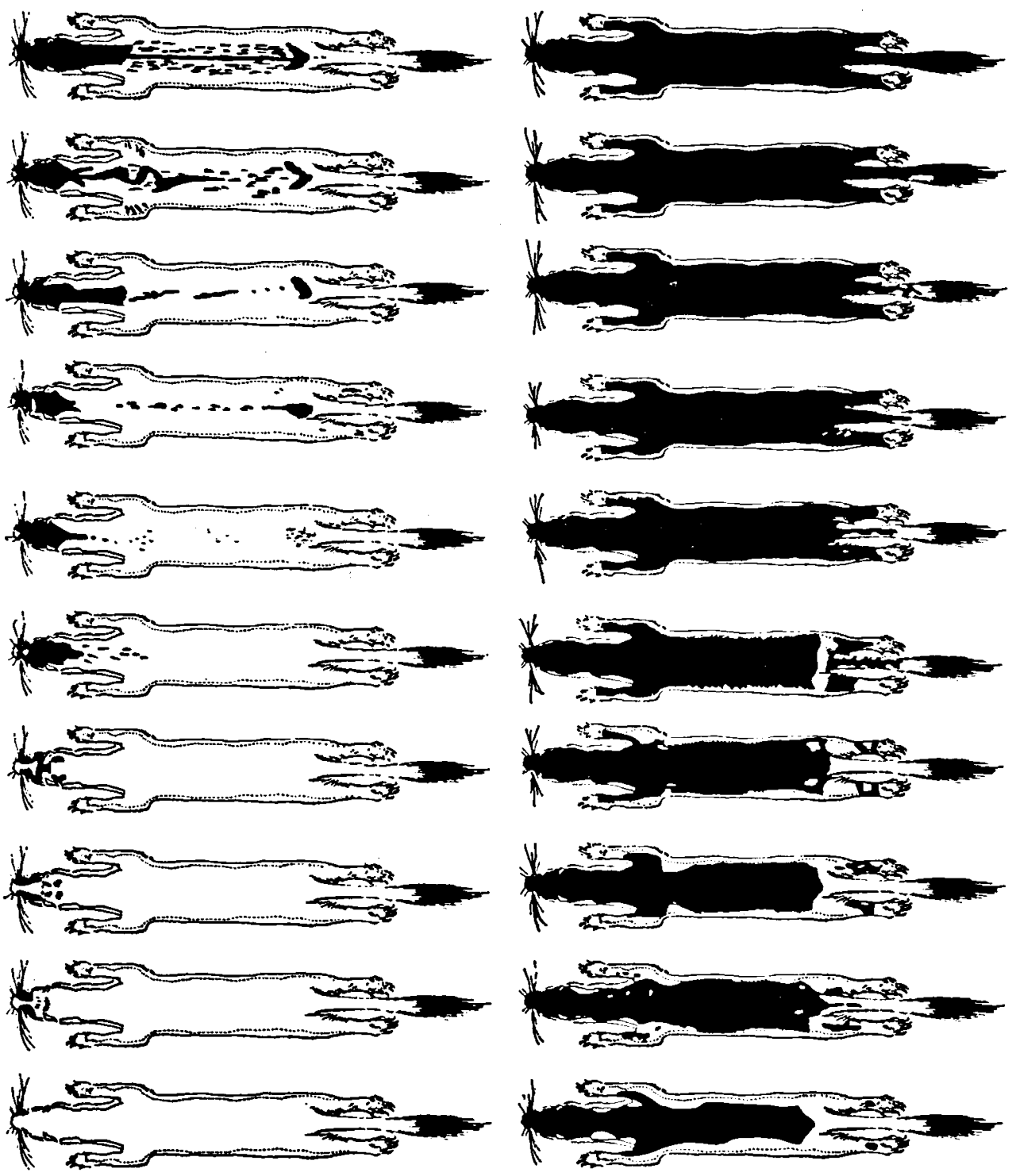
From these data it must be concluded, that the suggestion made by Frechkop (1954) cannot be substantiated. The illustrations clearly show nothing of a striped moult pattern, unless it has to be for the dorsal line, which is, however, fully explained by moulting ascending from the sides of the animals. The authors assume that Frechkop was misled by an abnormal pelt. Abnormal pelts do occur, though infrequently. In the collections used for this study, only one abnormal pelt was found among 299 normal pelts. This particular pelt (reg. nr. RMNH 269) is illustrated in fig. 2, below at right. In comparing its coat pattern with the coat of the other animals illustrated in fig. 2 , one notices that it is the reverse of the normal pattern. It must be said, Frechkop (loc. cit.) based his theory on only one aberrant specimen (Brussels Museum, reg.nr. 7911) amongst about 110 normal pelts of Stoats he studied.

\section{Starting and finishing date of the moult (fig. 3).}

Van Bree (1961) supplied data on this subject based on examinations of 134 pelts. These same pelts were used again together with pelts received later to ob- tain a more detailed view of this matter. The authors used the division of the animals in three groups as in van Bree (loc. cit.):

a. Animals with entirely brown upper sides and tails. In fig. 3 these are represented by the dark columns.

b. Animals with white and brown hairs on the upper sides and/or tails.

In fig. 3 these are represented by the hatched columns.

c. Completely white animals.

In fig. 3 these are represented by the white columns.

In fig. 3 each column contains the amount of brown, white and mixed specimens expressed in percentages of the total amount of animals per 10 days. The number of animals per decade varied between 2 (last decade of March) and 32 (last decade of October). The mean number was 8.2 per decade.

From fig. 3 we see that the first specimens with mixed upper pelage appear in the first decade of November, not as van Bree (loc. cit.) stated after the 20 th of November. The first completely white animal

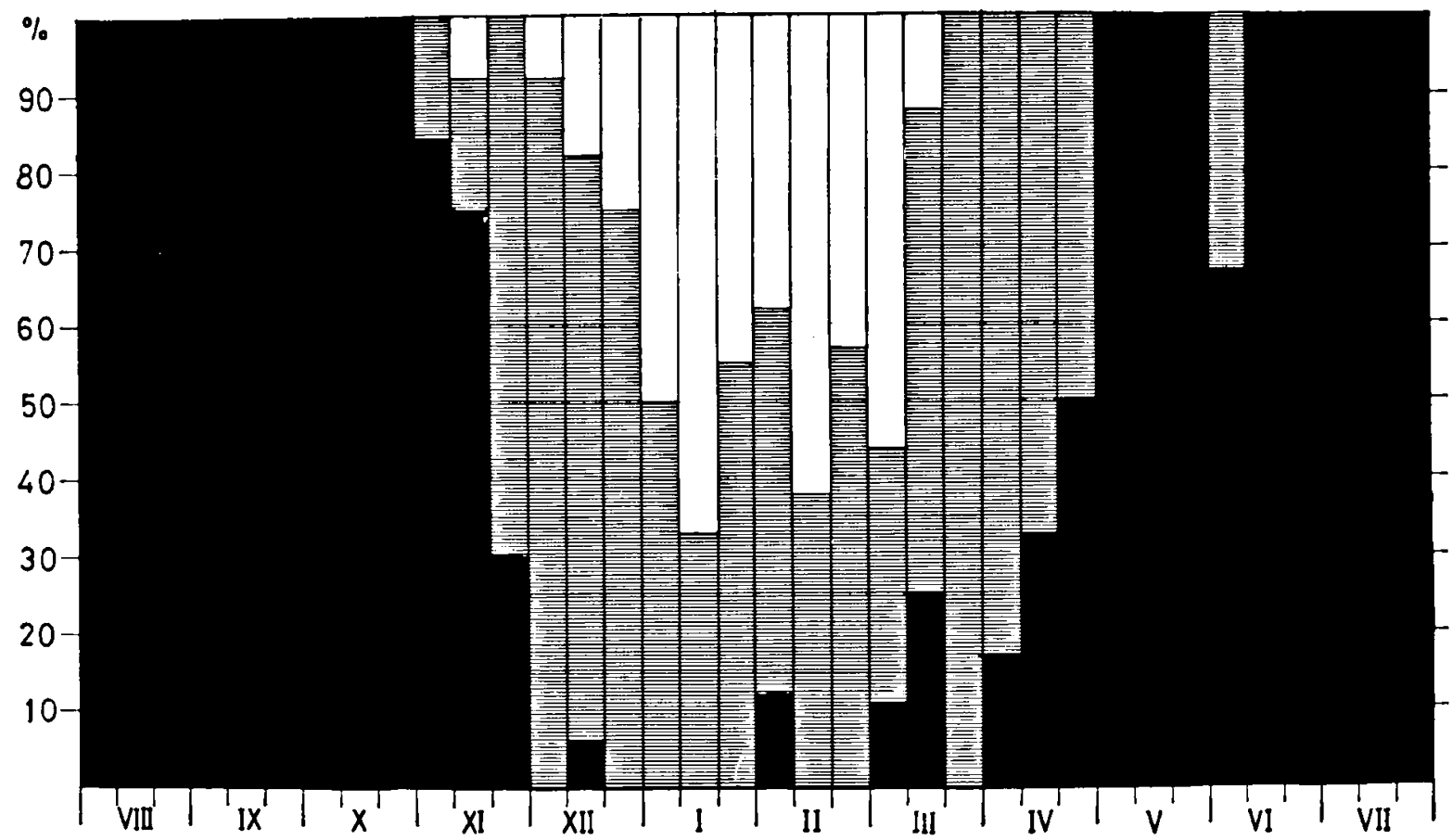

Fig. 3. Starting and finishing date of the moult in Mustela erminea from the Netherlands. On the absciss the months are given, divided into decades; on the ordinate the percentages of animals per decade with brown (black in the figure), variegated (hatched) and white upper pelage. 
appears in the second decade of November (van Bree gives the 10th of December). However, this first appearance is an isolated case. From the first decade of December onwards, the appearance of white animals is continuous until the second decade of March in accordance with van Bree's statement. Animals with variegated upper pelage occur continuously until the end of April (van Bree gives the 10th of April), with an isolated occurrence at the beginning of June (one animal). Entirely brown animals disappear in the last decade of November and reappear in the first decade of April. Thus we find that the period of time between the occurrence of $100 \%$ brown animals and $100 \%$ variegated/white animals is one month, both in the Autumn and in the Spring change of pelage. The appearance of entirely brown animals in the period between the 1st of December and the 1st of April, however, does occur. The authors encountered brown animals in the second decade of December, the first decade of February and the first and second decade of March.

\section{Differences between males and females.}

300 pelts were not enough to establish a definite difference between males and females. Although the result of the comparison does not warrant a conclusion, there are indications, that female Stoats accomplish their Spring moult faster than the males. No female Stoat has a variegated upper pelage after the 20th of March, whilst the last male with a variegated upper pelage was recorded at the end of April.

Various explanations of this phenomenon can be found if the indication proves to be correct. It is probable, that there will be a correlation with the reproductive cycle of the Stoat. Female Stoats become pregnant (implantation of the fertilized eggs) in March or April (Deanesley, 1935) and it is conceivable, that moulting cannot be associated either hormonally or metabolically with pregnancy. Much less could it be associated with lactation.

\section{Differences between COLDER and Warmer REGIONS.}

Mörzer Bruyns \& Westhoff (1951) supply data on the mean daily air temperatures for January in the Netherlands. From these data a rough division can be made between the southern plus western parts of the Netherlands (with a mean maximum temperature in January of about $4.7^{\circ} \mathrm{C}$ ) and the northern plus eastern parts (mean temperature about $3.8^{\circ} \mathrm{C}$ ). The warmer regions include the provinces of North and South Holland, Zeeland, the western and south- ern parts of North Brabant and the south of Limburg. All the other provinces belong to the colder region, which comprises the Frisian islands, the eastern parts of North Brabant and the northern part of Limburg; see fig. 4. The authors realize, however, that this climatic difference is rather small.

In comparing the above mentioned regions, the authors found no difference in the starting date of the Autumn moult nor in the finishing date of the Spring moult. A rather striking difference, however, appeared to exist in the number of completely white animals in both regions. When one takes into account only the animals with variegated or completely white coats, the percentage of totally white animals is 17 (13 individuals) in the warmer region and 53 (21 individuals) in the colder region; the percentages of the variegated animals being respectively 83 (63 individuals) and 47 (19 individuals). This suggests that there must be Stoats which stay variegated all winter. For the southernmost part of the Netherlands this has already been noted by Waage (1938: 153).

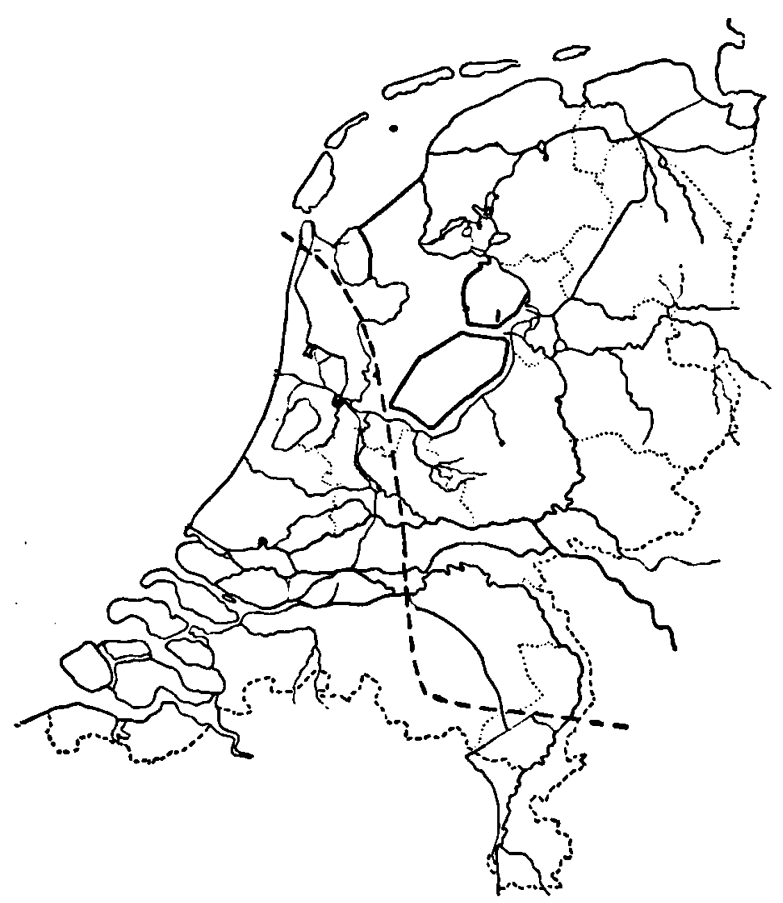

Fig. 4. Map of the Netherlands showing the division between the southern and western parts with a mean maximum temperature of about $4.7^{\circ} \mathrm{C}$. in January and the northern and eastern parts with a mean maximum terperature in January of about $3.8^{\circ} \mathrm{C}$. After Mörzer Bruyns \& Westhoff, 1951. 


\section{DISCUSSION}

Many authors have paid attention to the problem of temperature influence in the moult of the Stoat. Bissonnette \& Bailey (1944) made clear by extensive laboratory experiments, that the moulting is initiated by the decreasing daylight in Autumn and by the increasing daylight in Spring. They state that there is no influence of temperature on moult nor on colour change. Psenner (1942) and Herter (1958) confirm this statement on the basis of observations on animals held in captivity, whilst Schmidt (1954) opposes this view on the same basis. Rust (1962) concludes from his experiments that there is a delay of the Spring moult at low temperatures. Rothschild (1942), however, found that temperature did not affect the starting date of the moult, but that it influenced its duration. She noticed, that decreased temperature induces a colour change. Krumbiegel (1935) remarked, that the moult starts at the extremities, which are the parts most exposed to temperature changes. Flinthoff (1935) found, in comparing animals captured in the lowlands (temperature relatively high) with those in the highlands (temperature relatively low), that the latter turned white or variegated more frequently than the former.

Hall (1951 : 37) indicated on a map of North America the region where both the brown and the white winter pelage of Mustela frenata Lichtenstein, 1831, a species closely related to the Stoat, are found. In the plains this ribbon-like region follows the meridians; but to the west the northernmost extension of this region is found at the western slopes of the Rocky Mountains, where winter temperatures are relatively high.
In approaching this problem, it is important to make a distinction between moulting and colour change. Moulting is initiated by light impulses (day length), but that does not necessarily mean a colour change, for animals in southern regions stay brown, although there is an Autumn and Spring moult. Temperature apparently influences the colour change in causing the animal to turn white or not and causing the presence of Stoats which have a variegated upper coat all winter.

\section{SUMMARY}

1. A detailed study was made of the subsequent stages in the colour change of the Stoat, Mustela erminea Linnaeus, 1758.

2. Starting and finishing date of both Autumn and Spring moult were determined, based on the examination of 300 pelts from the Netherlands.

3. An indication was found for the existence of a difference in finishing date of the Spring moult in male and female Stoats. The examinations showed that female Stoats complete their summercoat a good month earlier than miles.

4. It appeared that there is a remarkable difference in number of completely white animals between warmer and colder parts in the Netherlands. The colder regions hold much more completely white animals. This indicates that temperature has an influence on whether Stoats turn completely white or have a variegated wintercoat.

\section{REFERENCES}

Bissonnette, T. H. \& Banley, E. E., 1944: Experimental modification and control of molts and changes of coatcolour in weasels by controlled lightning. New York Acad. Sci. Ann. (New York) 45, 221-260.

Bree, P. J. H. van, 1961: A note on the date of molt in the stoat (Mustela erminea L.) from the Netherlands. Säugetierk. Mitt. 9, 8-10.

DeAnesly, R., 1935: The reproductive processes of certain mammals. Part IX: Growth and reproduction in the stoat (Mustela erminea). Phil. Trans. B., 225, 1-62.

Fuinthoff, R. J., 1935: Stoats and weasels, brown and white. North Western Nat. 10, 214-29.

Frechrop, S., 1954: La mue de l'Hermine et le dessin du pelage chez les Mustélidés. Bull. Inst. Roy. Sc. nat. Belgique, 30, 1-14.

Hald, E. R., 1951: American weasels. Publ. Mus. nat. Hist. Univ. Kansas, 4, 1-466.
Herter, K., 1958: Ueber den Haarwechsel eines Hermelins. Zool. Beitr. (Berlin) 4, 135-41.

Krumbiegel, I., 1935: Gefangenhaltung und Farbwechsel der Wiesel. Zool. Garten (N.F.) 8, 8-15.

Mörzer BruYns, M. F. \& WesthofF, V., 1951: The Netherlands as an environment for insect life. 1-67 (Ned. Entomologische Vereniging - Amsterdam).

Psenner, H., 1942: Der Farbwechsel beim Hermelin. Zool. Garten (N.F.) 14, 149-53.

Rothschild, M., 1942: Change of pelage in the stoat Mustela erminea L. Nature (London) 149, 78.

Rust, C. C., 1962: Temperature as a modifying factor in the spring pelage change of short-tailed weasels. J. Mammalogy 43, 323-28.

Schмmт, F., 1954: Beobachtungen bei der Aufzucht von Hermelinen. Säugetierk. Mitt. 2, 166-74.

WAAGE, G. H., 1938 in: D. C. van Schaik Ed. - De Sint Pietersberg. 1-388, 4 maps (Leiter-Nypels, Maastricht). 